\title{
Erlotinib Response in a Non-Small Cell Lung Cancer Patient with EGFR Exon 20 Mutation
}

\author{
Levent KORKMAZ ${ }^{1}$, Mehmet ARTAC ${ }^{1}$, Mustafa KARAAGAC ${ }^{1}$, Zehra ER ${ }^{1}$, Melih C. BORUBAN ${ }^{1}$, \\ Necdet POYRAZ ${ }^{2}$, Bugra KAYA ${ }^{3}$, Lema TAVLI ${ }^{4}$, Kemal ODEV ${ }^{2}$ \\ ${ }^{1}$ Necmettin Erbakan University, Meram Faculty of Medicine, Departmant of Medical oncology \\ ${ }^{2}$ Necmettin Erbakan University, Meram Faculty of Medicine, Departmant of Radiology \\ ${ }^{3}$ Necmettin Erbakan University, Meram Faculty of Medicine, Departmant of Nuclear Medicine \\ ${ }^{4}$ Necmettin Erbakan University, Meram faculty of medicine, Departmant of Pathology, Konya, TURKEY
}

\section{Dear Editor,}

Targetted therapies like epidermal growth factor receptor tyrosin kinase inhibitors (EGFR-TKI) have changed the treatment options of non small cell lung cancer (NSLC) in the last decade. EGFR mutations have been described as a predictive marker for EGFR-TKI therapy in NSCLC. EGFR-mutant NSCLC was recognized as a different molecular subset of lung cancer. Tumors with these mutations are highly sensitive to EGFR-TKIs, such as gefitinib and erlotinib. ${ }^{1}$

EGFR mutations are present mostly among neversmokers, women, patients diagnosed with adenocarcinoma, and those of East Asian ethnicity. While the prevalence of EGFR mutations is approximately 50\% - 65\% among East Asians and 10\% - 15\% among Western countries, prevalance of EGFR mutations in Turkish NSCLC patients is $44 \%$ and similar to those seen in the Eastern countries. ${ }^{2}$ The most common EGFR mutations in patients with NSCLC include short in-frame deletions in exon 19 and a specific point mutation in exon 21 at codon 858 , responsible from approximately $80 \%$ - $90 \%$ of detected EGFR mutations. EGFR-TKIs are more effective against NSCLCs with an EGFR exon 19 deletion when compared with exon 21 L858R mutation. ${ }^{3}$

Exon 20 mutations were the reasons for primary resistant to EGFR-TKIs. The most common mechanism is acquired resistance of an EGFR exon 20 T790M mutation detected after disease progression on EGFR-TKIs. ${ }^{4}$ Herein, we presented erlotinib response in a smoker Turkish male with metastatic lung adenocarcinoma characterized by a rare exon 20 mutation.

In July 2011, a 54-year-old Turkish male smoker (40 package of year) who suffered from coughing and hemoptysis occasionally was admitted to our hospital. There was a lesion in chest radiograph on the right side and another right hilar lesion confirmed with computerized tomography of thorax, also. For staging the patient, positron emission tomography (PET) scan performed and showed a lesion 19x17 mm (maximum Standardized Uptake Value (SUV max: 3.54) in upper posterior lobe and the other lesion 22x33 mm (SUV max: 3.50) in hilar region of the right lung. Pathologic examination of transthoracic biopsy of mass in the right lung revealed adenocarcinoma. ALK re-arrangement was not detected and EGFR gene assessment could not be performed at that time because of insufficient biopsy material. He was treated with 6 courses of paclitaxel/carboplatin chemotherapy from July 2012 to December 2012. Until May 2013 the patient obtained disease stabilization. In May 2013 due to the disease progression on chest computerized tomography (CT) the patient received second-line treatment with pemetrexed/cisplatin. After 4 cycles, the CT scan showed further progression, with multiple new metastases in liver. 


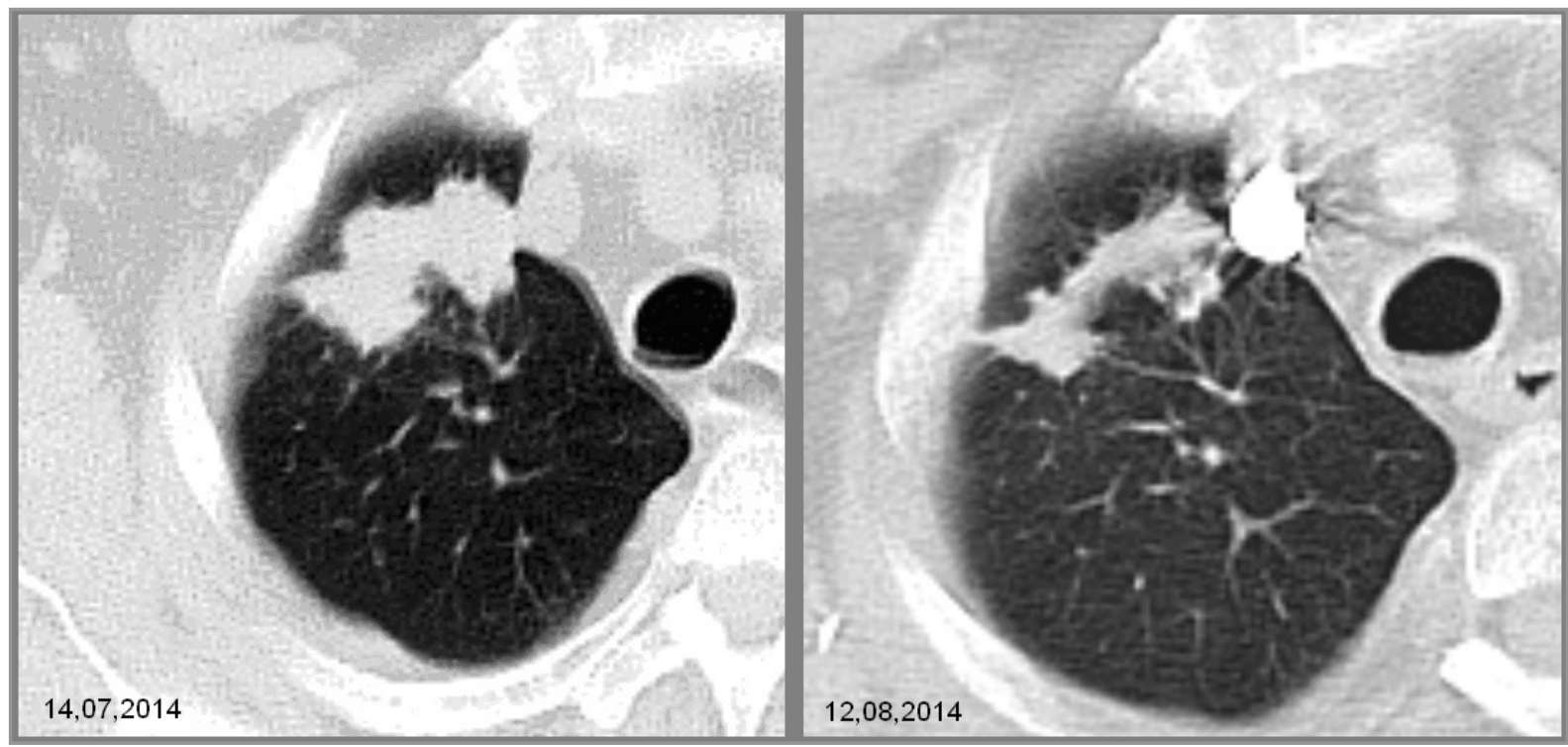

Figure 1. Regression in computerized tomographies in one month with erlotinib treatment

Thus vinorelbine was started in September 2013. After 3 cycles, CT imaging showed again progression in liver metastases. Cisplatin/etoposide chemotherapy was prefered for the 4th line treatment, because performance score was still very good.

After 3 cycles of treatment the disease progression was observed in chest CT. 5th line treatment with gemsitabin was performed to the patient for 6 cycles. After single agent gemcitabin, progression was detected in liver metastases and biopsy was performed from liver for EGFR gene analyze because of insufficient material in the first biopsy. We detected p.Q787Q (c.2361G >A) mutation in exon 20. The patient received erlotinib at the dose of 150 $\mathrm{mg}$ daily in july-2014. CT scan was performed one month later and showed regression in pulmonary lesions and stable lesions in liver (Figure 1). Thus, the patient continued to receive erlotinib. After 2 months of receiving erlotinib, he died at his home with an unknown reason.

\section{DISCUSSION}

It has been confirmed that EGFR-activating mutations represents the main predictor of clinical outcome with TKI therapy. ${ }^{5}$ Primary resistance to TKI therapy is mostly associated with mutation at exon $20 .{ }^{6}$ However, especially the presence of EGFR exon 20 mutations in lung cancer progression be- fore TKI therapy is still being debated. Conversely to this primary resistance, in our patient with a rare mutation in exon 20 showed good response to erlotinib.

According to Wang et al. ${ }^{7}$ when EGFR-TKI is used before chemotherapy the clinical response for the drug will be maximized. Recent data also suggest that erlotinib should be used as first-line systemic therapy in patients with EGFR mutations documented before the mentioned therapy. ${ }^{8}$ But, like in our case, we can say that even though patients receive multiple chemotherapy series, EGFR-TKI can be chosen for treatment.

Xing et al. ${ }^{9}$ published a case report showing a good clinical response to erlotinib after platinum-based chemotherapies. In that case a mutation in exon 20 of EGFR in a Chinese male non-smoker was found. He was diagnosed with stage IV lung adenocarcinoma and characterized by the codon 769 point mutation GTG>GCG, which translates into alanine instead of valine (p.V769A). He received erlotinib after multiple chemotherapy series but he was a non-smoker conversely to our case.

Arcila et al. ${ }^{10}$ evaluated EGFR exon 20 insertion mutations in lung adenocarcinomas, identified 33 EGFR exon 20 insertion cases and all of them are mutually exclusive with mutations in the other genes tested (except PIK3CA). The patients were more common among never-smokers $(\mathrm{p}<0.0001)$. 
Our patient had 40 pack years of smoking. Like other EGFR mutations exon 20 mutations can also be found in smokers also.

In conclusion, EGFR exon 20 mutations are more common among never-smokers, however they should be assessed in smokers also. We suggest that this rare mutation p.Q787Q (c.2361G $>$ A) in EGFR exon 20 may be sensitive to TKI therapy in NSCLC. The identification of EGFR mutations provides new predictive biomarkers for TKI therapy and is essential for the successful use of targetted therapies.

\section{REFERENCES}

1. Pao W, Miller V, Zakowski M, et al. EGF receptor gene mutations are common in lung cancers from "never smokers" and are associated with sensitivity of tumors to gefitinib and erlotinib. Proc Natl Acad Sci USA 101: 13306-13311, 2004.

2. Bircan S, Baloglu H, Kucukodaci Z, et al. EGFR and KRAS mutations in Turkish non-small cell lung cancer patients: a pilot study. Med Oncol 31: 87, 2014.

3. Jackman DM, Yeap BY, Sequist LV, et al. Exon 19 deletion mutations of epidermal growth factor receptor are associated with prolonged survival in non-small cell lung cancer patients treated with gefitinib or erlotinib. Clin Cancer Res 12: 39083914, 2006.

4. Mitsudomi T, Yatabe Y. Mutations of the epidermal growth factor recep $\neg$ tor gene and related genes as determinants of epidermal growth factor receptor tyrosine kinase inhibitors sensitivity in lung cancer. Cancer Sci 98: 1817-1824, 2007.

5. Fukuoka M, Yano S, Giaccone G, et al. Multiinstitutional randomized phase II trial of gefitinib for previously treated patients with advanced non-small-cell lung cancer. J Clin Oncol 21: 2237-2246, 2003.

6. Pao W, Miller VA, Politi KA, et al. Acquired resistance of lung adenocarcinomas to gefitinib or erlotinib is associated with a second mutation in the EGFR kinase domain. PLoS Med 2: e73, 2005.
7. Wang $\mathrm{Y}$, Bao W, Shi H, et al. Epidermal Growth Factor Receptor Exon 20 Mutation Increased in Post-Chemotherapy Patients with Non-Small Cell Lung Cancer Detected with Patients' Blood Samples. Transl Oncol 6: 504-510, 2013.

8. Rosell R, Carcereny E, Gervais R, et al. Spanish Lung Cancer Group in collaboration with Groupe Français de PneumoCancérologie and Associazione Italiana Oncologia Toracica Erlotinib versus standard chemotherapy as first-line treatment for European patients with advanced EGFR mutationpositive non-small-cell lung cancer (EURTAC): a multicentre, openlabel, randomised phase 3 trial. Lancet Oncol 2012: 13: 239246, 2012.

9. Xing $\mathrm{K}$, Zhou $X$, Zhao $X$, et al. A novel point mutation in exon 20 of EGFR showed sensitivity to erlotinib. Med Oncol 31: 36, 2014.

10. Arcila ME, Nafa K, Chaft JE, et al. EGFR exon 20 insertion mutations in lung adenocarcinomas: prevalence, molecular heterogeneity, and clinicopathologic characteristics. Mol Cancer Ther 12: 220-229, 2013.

\section{Correspondence}

Dr. Levent KORKMAZ

Necmettin Erbakan Üniversitesi Tip Fakültesi

Tibbi Onkoloji Anabilim Dali

42080 KONYA / TURKEY

Tel: (+90-332) 2236484

Fax: (+90-332) 2237849

e-mail: drlev2002@hotmail.com 